\title{
MODEL HIERARKI KOMUNIKASI ORGANISASI BADAN RESERSE DAN KRIMINAL KEPOLISIAN REPUBLIK INDONESIA (BARESKRIM POLRI)
}

\author{
Dadang Hartanto \\ Universitas Muhammadiyah Sumatera Utara, Indonesia \\ dadanghartanto@umsu.ac.id
}

\begin{abstract}
Abstrak
Tugas pokok yang dijalankan oleh organisasi Polri dibentuk secara nasional dengan konsep organisasi berjenjang mulai dari tingkatan yang bersifat fungsional antara lain fungsi Intelijen, Reserse, Sabhara, Lalu Lintas dan Pembinaan Masyarakat. Namun dalam implementasinya hierarki komunikasi organisasi yang dikembangkan belum berjalan optimal. Tujuan penelitian ini adalah mengkaji tentang model hierarki komunikasi organisasi Badan Reserse dan Kriminal Kepolisian Republik Indonesia (Bareskrim Polri). Penelitian ini menggunakan jenis penelitian kualitatif yaitu peneliti mengeksplorasi suatu entitas atau fenomena (kasus) dan aktivitas (program, kejadian, proses, institusi, atau kelompok) terkait pembelajaran di Bareskrim Polri. Pengumpulan data dilakukan dengan metode wawancara dengan informan kunci. Metode ini ditujukan untuk mendapatkan database informasi yang ada pada setiap informan yaitu Pimpinan Polri/Kabareskrim Polri atau Wakabareskrim, Direktur/Wakil Direktur Bareskrim Polri, Karo Wasidik, Kasub Dit, Kanit, Penyidik. Teknik analisis data dilakukan dengan membaca dan memahami berbagai materi emperik (emperical material) yang telah dikumpulkan tersebut kemudian mengkaitkannya dengan key themes pada penelitian ini. Hasil penelitian ini membuktikan bahwa model hierarki komunikasi mengarahkan kepada siapa anggota organisasi berinteraksi dan berkomunikasi sehingga tidak dianggap salah (secara etika dan displin) baik dalam bersikap dan berperilaku khususnya dalam hubungan person to person. Di sisi lain, juga mempunyai hubungan dan saling terkait yaitu mempengaruhi pengelolaan organisasi yang muncul dalam bentuk keputusan, kebijakan dan arahan baik tertulis maupun lisan. Model hierarki komunikasi mendorong terjadinya manajemen pembelajaran yang tertib karena selain tetap membuka pola komunikasi dua arah, diskusi dan dialog serta di dalamnya ada kritik, masukan dan saran. Namun model komunikasi hierarki mensyaratkan komunikasi tersebut secara formal harus berpedoman pada etika, prosedur dan tata cara tertentu.
\end{abstract}

Kata kunci: Hierarki, Komunikasi, Organisasi, Bareskrim

\begin{abstract}
The purpose of this study is to examine the hierarchical model of organizational communication for the Indonesian National Police (Bareskrim Polri). This research uses a qualitative research type, namely, researchers explore an entity or phenomenon (cases) and activities (programs, events, processes, institutions, or groups) related to learning at the Police Criminal Investigation Unit. Data collection was carried out by the interview method. This method is intended to obtain a database of information on each informant. The analysis technique is done by reading and understanding various empirical materials that have been collected and then linking them to the key themes in this study. The results of this study prove that the hierarchical communication model directs to whom the members of the organization interact and communicate so that they are not considered wrong (ethically and disciplinarily) both in attitude and behavior, especially in person to person relationships. On the other hand, it also has a relationship and is interrelated, namely influencing organizational management that appears in the form of decisions, policies, and directions both written and oral. The hierarchical communication model encourages orderly learning management because apart from keeping open twoway communication patterns, discussions, and dialogues, and includes criticism, input, and suggestions. However, the hierarchical communication model requires that communication be formally guided by certain ethics, procedures, and procedures.
\end{abstract}

Keywords: Hierarchy, Communication, Organization, Bareskrim 


\section{PENDAHULUAN}

Karakteristik tugas penegakan hukum juga menempatkan Badan Reserse dan Kriminal (Bareskrim) untuk selalu berhadapan dengan tuntutan masyarakat dan berbagai kepentingan yang kondisinya tarik-menarik posisi penyidik Bareskrim sementara secara normatif dituntut untuk selalu obyek, independen dan semata-mata berpedoman pada aturan hukum dan rasa keadilan masyarakat. Kesuksesan Bareskrim dalam melaksanakan tugas ditentukan oleh kepekaan dan kemampuan memprediksi perkembangan lingkungan kedepan dan dampaknya pada tugas serta organisasi, kemampuan analisis dan menemukan berbagai fakta, data dan informasi, pemahaman berbagai peraturan perundang-undangan untuk mengungkap perkara dan menetapkan pelaku kejahatan atau tersangka serta kemampuan mengelola sumberdaya organisasi untuk diarahkan mendukung pencapaian visi organisasi. Bareskrim dalam upaya pengungkapan perkara dan kejahatan juga memerlukan kerjasama dan melibatkan stakeholders. Role compotition seluruh stakeholders yang bertautan dengan tugas penegakan hukum diidentifikasi, dikelola dan didayagunakan oleh Bareskrim agar dalam pelaksanaan tugas menyelesaikan proses tindak pidana dapat cepat, obyektif serta mampu menyajikan alat bukti kejahatan yang tidak terbantahkan. Bareskrim sebagai organisasi yang belajar juga ditunjukan dari kepeduliannya terhadap keluhan masyarakat.

Seiring dengan pergantian paradigma polisi guna menjalankan salah satu fungsi pemerintahan, maka posisi kepolisian dalam organisasi negara menjadi salah satu faktor yang memiliki pengaruh dominan dalam penyelenggaraan kepolisian secara proporsional dan professional sebagai syarat pendukung terwujudnya pemerintahan yang baik (good governance). Pemerintahan yang baik dapat terwujud manakala didukung oleh penyelenggara fungsi pemerintahan yang baik. Dengan demikian penyelenggaraan kepolisian yang melaksanakan salah satu fungsi pemerintahan akan dapat mendukung pemerintahan yang baik bila terwujud kepolisian yang baik (good police) $)^{1}$. Oleh karena itu di mana kedudukan kepolisian dalam melaksanakan fungsinya di bidang keamanan dan ketertiban masyarakat, maka perlu dikaji bagaimana pembelajaran organisasi Bareskrim dalam menjalankan hierarki komunikasi dalam lingkungan internal organisasi, sehingga kepolisian benar-benar menjadi lembaga yang mandiri, modern, proporsional dan profesional sejalan dengan tuntutan dan harapan masyarakat yang bertumpu pada kepolisian yang baik (goodpolice).

\footnotetext{
1 Ida Bagus Kade Danendra. 2012. Kedudukan Dan Fungsi Kepolisian Dalam Struktur Organisasi Negara Republik Indonesia. Jurnal Lex Crimen Vol.I, No.4
} 


\section{TINJAUAN TEORITIS}

\section{Model Hierarki Komunikasi Organisasi}

Melakukan komunikasi lebih rumit dari sekedar mentransfer informasi. Sebenarnya komunikasi adalah tindakan interaktif untuk membangun makna pesan tertentu, atau program atau inovasi tertentu, tergantung pada kasusnya, oleh orang-orang yang terlibat dengannya dan satu sama lain. Jika keterlibatan ini tidak terjadi, informasi mungkin telah berpindah dari satu tempat ke tempat lain, dan dalam pengertian itu orang dapat mengatakan bahwa komunikasi telah terjadi. Organisasi membutuhkan komunikasi untuk merampingkan mereka tugas. Komunikasi dalam organisasi disebut formal organisasi. Komunikasi dalam organisasi adalah proses pengiriman dan penerimaan semua organisasi pesan melalui kelompok formal dan informal di organisasi ${ }^{2}$. Organisasi dibentuk dengan menggunakan manajemen yang mumpuni untuk menyadari tujuan organisasi. Komunikasi membangun hubungan, termasuk hubungan kerja yang memungkinkan orang-orang di dalam organisasi mengoordinasikan upaya mereka untuk kebaikan bersam ${ }^{3}$ a. Untuk menghindari tumpang tindih atau lubang dalam pekerjaan yang akan merusak koordinasi, mengembangkan usaha kecil pada akhirnya harus membangun struktur organisasi ${ }^{4}$. Struktur tersebut tidak hanya menetapkan tempat setiap orang, tetapi juga menetapkan hierarki komunikasi. Hierarki itu bertumpu pada koneksi yang ditetapkan dalam struktur. Koneksi ini menentukan saluran komunikasi formal ${ }^{5}$. Model hierarki adalah model di mana tingkat yang lebih rendah diurutkan di bawah hierarki unit tingkat yang lebih tinggi berturut-turut. Organisasi hierarki adalah struktur organisasi di mana setiap entitas dalam organisasi, kecuali satu, berada di bawah satu entitas lain ${ }^{6}$. Sebuah organisasi biasanya memiliki hierarki yang terdiri dari satu/kelompok kekuasaan di puncak dengan tingkat kekuasaan berikutnya di bawah mereka ${ }^{7}$.

Model komunikasi hirarkis diartikan sebagai pertukaran informasi dan mempengaruhi

\footnotetext{
2 Widhiastuti, H. 2012. The Effectiveness of Communications in Hierarchical Organizational Structure. International Journal of Social Science and Humanity. Vol. 2, No. 3

${ }^{3}$ Muhammad Yahaya, et. al. 2018. Organizational Structure And An Effective Communication: The Moderating Effect Of Transformational Leadership. International Journal Of Scientific \& Technology Research Volume 7, Issue 11, November 2018

${ }^{4}$ https://www.managementstudyhq.com/types-of-communication.html

5 Dewan, R., Seidmann, A., \& Sundaresan, S. (1997). Communications in Hierarchical Organizations and Standards Policies for Information Technology. International Journal of Electronic Commerce, 1(3), 43-63. Retrieved December 12, 2020, from http://www.jstor.org/stable/27750819

${ }^{6}$ Aukse Blazenaite. 2011. Effective Organizational Communication: in Search of a System. Socialiniai Mokslai, Vol. 4 (74)

${ }^{7}$ A. Harsono, Root Cause. 2008. Analysis Methods and Solutions, Makara Social Humanities Series Journal, Vol 12, pp. 72- 81
} 
anggota organisasi, karena ada keterlibatan antara satu sama lain, pimpinan dan bawahan dalam organisasi formal. Pimpinan menyediakan lima jenis informasi melalui komunikasi kepada bawahan, yaitu instruksi pekerjaan, alasan pekerjaan, prosedur dan praktik organisasi, umpan balik tentang kinerja, dan indoktrinasi tujuan organisasi ${ }^{8}$. Selain itu, bawahan mengkomunikasikan informasi tentang diri mereka sendiri kepada pimpinan, rekan kerja dan masalah mereka, praktik dan kebijakan organisasi, dan apa yang perlu dilakukan dilakukan dan bagaimana melakukannya.

\section{METODE}

Dalam melaksanakan penelitian, menggunakan jenis penelitian kualitatif. Peneliti menyelidiki secara cermat pembelajaran dalam pembelajaran organisasi. Pemilihan strategi ini didasarkan pada alasan bahwa peneliti mengeksplorasi suatu entitas atau fenomena (kasus) dan aktivitas (program, kejadian, proses, institusi, atau kelompok) terkait pembelajaran di Bareskrim Polri, yang dilakukan dengan mengumpulkan secara detail berbagai data dan informasi sesuai dengan prosedur pengumpulan data selama periode waktu tertentu. Periode tersebut disebut sebagai database realitas yang diidentifikasi dalam penelitian sebagai kondisi aktual Bareskrim. Dengan demikian hasil yang diperoleh pada suatu lokus pada penelitian studi kasus ini hanya berlaku untuk lokus yang diteliti saja dan tidak dapat dipresentasikan pada lokus yang lain. Pengumpulan data dilakukan dengan metode wawancara. Metode ini ditujukan untuk mendapatkan database informasi yang ada pada setiap informan. Information database yang ditarik terkait dengan informasi dan penjelasan-penjelasan tentang operasional variabel atau fenomena yang diteliti.

Pada strategi wawancara, peneliti melakukan komunikasi face to face, atau melakukan interview agar dapat mendalami secara langsung reaksi, emosi dan makna yang diungkapkan oleh informan. Strategi ini juga dilakukan untuk menggali makna dan ungkapan khusus yang dipahami anggota organisasi Bareskrim. Konfirmasi dan penjelasan lebih dalam terkait data dan informasi dilakukan melalui komunikasi telepon maupun short message service (sms). Hasil dari wawancara berupa audio di transkrip menjadi data tertulis dan studi literer dikumpulkan. Teknik analisis dilakukan dengan membaca dan memahami berbagai materi emperik (emperical material) yang telah dikumpulkan tersebut kemudian mengkaitkannya dengan key themes pada penelitian ini.

\footnotetext{
${ }^{8}$ Krackhardt Hanson, 1993. Informal Network: The Company Behind the Chart, Harvard Business Review, pp.63,July/Agust,
} 


\section{HASIL DAN PEMBAHASAN}

Model hierarki komunikasi merupakan gambaran internal anggota organisasi yang memahami bahwa organisasi dikelola dan bekerja didasarkan pada tata hubungan, interaksi, sikap dan perilaku di antara anggota organisasi yang berpedoman pada hierarki dengan jenjang kepangkatan yang bersifat hierarkis ${ }^{9}$. Model ini melekat pada setiap diri anggota organisasi dibentuk oleh pengetahuan dan pengamatan realisasi pranata dan norma serta berbagai hal yang pernah dialami di dalam kehidupan organisasi ${ }^{10}$ khususnya terkait dengan hierarki. Organisasi kepolisian memiliki pengaturan (norma) hierarki yang didasarkan pada strata golongan kepangkatan yaitu Tamtama, Brigadir, Perwira. Pada golongan Tamtama terdapat 6 level, Brigadir 6 level, dan Perwira memiliki tiga golongan, Perwira Pertama 3 level, Perwira Menengah 3 level dan Perwira Tinggi 4 level.

Setiap jenjang kepangkatan ini memiliki lambang yang berbeda, lambang tersebut nampak jelas pada seragam dinas Polri. Meskipun anggota Bareskrim ketika pada tugas sehari-hari tidak menggunakan seragam dinas (un uniform police) tetapi, model hierarki tetap mengarahkan dengan siapa anggota organisasi berinteraksi sehingga tidak dianggap salah (secara etika dan displin) baik dalam bersikap dan berperilaku khususnya dalam hubungan person to person ${ }^{11}$. Cara berbicara, tutur kata dan gerak tubuh (gesture) sangat dipengaruhi oleh model hierarki komunikasi. Disamping itu, juga mempunyai hubungan dan saling terkait. Dalam implementasinya mempengaruhi pengelolaan organisasi yang muncul dalam bentuk keputusan, kebijakan dan arahan baik tertulis maupun lisan. Pada pembinaan sumber daya manusia, misalnya, promosi dan peningkatan karier dalam jenjang kepangkatan tetap memperhatikan senioritas ${ }^{12}$. Hal ini berarti personel Polri termasuk yang bertugas di Bareskrim pada tataran pimpinan dan pengambil keputusan dalam bersikap, bertindak dan berperilaku juga dipengaruhi dan mempertimbangkan faktor kepangkatan dan senior-yunior.

Model hierarki komunikasi mendorong terjadinya manajemen pembelajaran yang tertib karena selain tetap membuka pola komunikasi dua arah, diskusi dan dialog (sebagai salah satu displin) serta di dalamnya ada kritik, masukan dan saran, namun model komunikasi hierarki

\footnotetext{
${ }^{9}$ Brown, J. 1992. “Changing the Police Culture”, Policing, Vol 8, No 4, Winter. page 230-245.

${ }^{10}$ Johnson-laird,1983, Mental models, Library of Congress Catalog in Publicition Data, US of America.

${ }^{11}$ Shanahan, P. 2000. "Police Culture and the Learning Organisation: A Relationship?", AVETRA Conference Papers. Page 33

12 Peraturan Kapolri nomor 16 tahun 2012 tentang mutasi personel Polri, dalam pasal 4 angka 2 huruf e.
} 
mensyaratkan komunikasi tersebut secara formal harus berpedoman pada etika, prosedur dan tata cara tertentu. ${ }^{13}$ Informan pada level Direktur menyampaikan :

"Saya misalnya, ada noda di belakang saya, saya minta tolong diingetin. Siapa pun harus ada tata krama. Karena saya manusia biasa. Lupa itu mungkin. Kalo ada salah, silahkan, siapa pun sebelumnya juga gitu. Kalo ada salah tolong ungkap”

Model komunikasi hierarki juga memberikan pembelajaran individu terkait dengan kesadaran terhadap posisi pada level tertentu untuk selalu mengkoreksi diri sendiri sebagai hal pantas dan patut yang harus dimiliki oleh dirinya dalam posisi tersebut di dalam organisasi baik yang terkait dengan kompetensi maupun integritas. Temuan data pernyataan pimpinan organisasi.

"Oleh karenanya rekan-rekan sekalian saya mintakan dari kita yang diberi kepercayaan, temen-temen sekarang mengendalikan seluruh penyidik yang berada di bawah kendalinya untuk betul-betul mengawasi satu persatu dan jangan sampai Direktur sampai tingkat Direktur masih melakukan tindakan- tindakan yang menyimpang"

Keberadaan model komunikasi hierarki ini juga memaksa (pressure) anggota organisasi untuk belajar sesuai apa yang dikehendaki oleh atasannya ${ }^{14}$, informan mengungkapkan "Bagaimana cara menangani bagaimana permasalahannya, pendataan saya juga minta karena takut di pimpinan ada yang tanya, kita sudah siap”.

Selanjutnya sebagaimana telah disampaikan di atas bahwa model ini tidak membatasi komunikasi dialog dan diskusi yang membutuhkan kesetaraan antara anggota forum diskusi karena anggota organisasi telah melakukan pembelajaran sehingga mampu mengaktifkan dan menggunakan secara efektif model hierarrki komunikasi yang dimiliki sesuai situasi yang dihadapi dan tujuan yang akan dicapai. Pembelajaran ini juga telah memampukan organisasi membuat forum-forum diskusi dan dialog sehingga tercipta pertukaran pengetahuan dan persepsi. Informan menyampaikan:

\footnotetext{
${ }^{13}$ Hinshaw, R.E. 1980. “Anthropology, Administration and Public Policy”, Annual Review of Anthropology, 9: 497-522.

${ }^{14}$ Dalam pandangan Burt Nanus dan Stephen M. Dobbs bahwa "a leader is a person who marshals the people, capital, and intellectual resources of the organization to move it in the right direction". Seorang pemimpin mereka yang mampu bertindak sebagai komandan, mereka yang mempunyai kemampuan financial, integritas mendorong sumber daya organisasi untuk mencapai tujuan. Dengan demikian, pengaruh seorang pemimpin dapat tumbuh ketika ia mempunyai kekuatan memaksa, kemampuan materi serta kemampuan mendayagunakan organisasi. Keuatan memaksa dalam organisasi modern merupakan bentuk kepemimpinan otoriter. Lihat dalam Nanus, Burt and Stephen M. Dobbs, 1999, Leaders Who Make a Difference, JooseyBoss Publisher.
} 
"Ada, kita selalu menyampaikan perkembangan penyidikan, selain gelar perkara $^{15}$... bila ada pertentangan penyidik dan pemimpin...Kita mengikuti pimpinan, selama ini begitu, artinya kalau ada pemeriksaan atau ada gugatan ya kita juga mempunyai dasar kita menyampaikan pakai nota dinas bahwa langkah kita bertentangan dengan keputusan pimpinan. Nota dinas kita berupa saran, berbentuk tulisan... melalui kasubdit ke pada Direktur"...Karena gini, sistem di penyidikan jadi bisa dikatakan nggak ada atasan dan bawahan. Dalam artian semua gini. Semuanya adalah penyidik. Yang bedain adalah Perwira dan Bintara. Kalo Perwira adalah penyidik, kalo Bintara penyidik pembantu. Dan kita semua sharing. Dalam setiap melakukan pengungkapan atau ide-ide, kita lempar di floor".

Model hierarki komunikasi juga menguatkan pembelajaran pada pimpinan atau atasan terkait dengan tanggung jawab, keberanian dan penghitungan terhadap semua resiko dari keputusan dan kebijakan yang diambil dalam proses penyidikan dimana secara legalitas dikuatkan dengan “tanda-tangan”. Informan di level Panit menyampaikan:

"Intervensi dalam bentuk apa ..Di telepon, atau menghadap Direktur... Ya, kita sesuai dengan apa yang disampaikan ke pimpinan dan pimpinan yang mengambil kebijakan...Arahan dan informasi serta perintah ..Kalau asalnya dari pimpinan pasti dilaksanakan ...Ya kan kita punya hierarki, punya atasan, kalau memerintahkan, pasti kita laksanakan selama untuk kepentingan tugas pasti dilaksanakan. Pimpinan maupun senior, pangkat lebih tinggi ya kita menyesuaikan dengan kepangkatan...karena pimpinan yang menentukan arahnya dan dia akan tanda tangan".

Model hierarki komunikasi juga memberikan pembelajaran terhadap bawahan untuk selalu peduli dan menyesuaikan terhadap gaya kepemimpinan dan peran atasannya karena masih-masing atasan atau pimpinan mempunyai karakter berbeda-beda. Informan menyatakan

"hierarki, kita kan menyampaikan harus pas, kadang - kadang ada yang bisa menerima bagus, ada yang menerima kurang tepat".

Komunikasi yang efektif dan berbagi informasi antara pimpinan dan nawahan adalah hal yang mendasar prasyarat dalam strategi organisasi untuk terlibat secara positif di organisasi tempat mereka bekerja. Tujuan utamnya untuk dapat merumuskan kebijakan atau strategi komunikasi agar terhubung dengan organisasi secara keseluruhan. Salah satunya masalah utama yang dihadapi organisasi terletak pada persuasi untuk bekerja secara efektif demi

\footnotetext{
${ }^{15}$ Gelar perkara mekanisme pembahasan terhadap penanganan perkara yang dilaporkan masyarakat dalam bentuk kegiatan rapat atau forum yang dihadiri oleh pihak yang menangani perkara (penyidik), atasan penyidik dan pengawas internal. Pada pembahasan tersebut terjadi pernyataan pendapat, diskusi dan argumentasi serta kesimpulan sebagai suatu keputusan yang berisi masukan, koreksi dan saran kepada penyidik untuk menjalankan proses penyidikannya ke depan.
} 
kepentingan organisasi. Model hierarki komunikasi sangat penting dalam teori dan praktek organisasi sebagai faktor kontribusi terhadap kinerja.

Berikut ini gambaran hubungan bersifat hierarkhi yang membentuk model hierarki komunikasi serta saluran komunikasi yang tersedia mendukung terjadinya pembelajaran didalam organisasi $^{16}$.
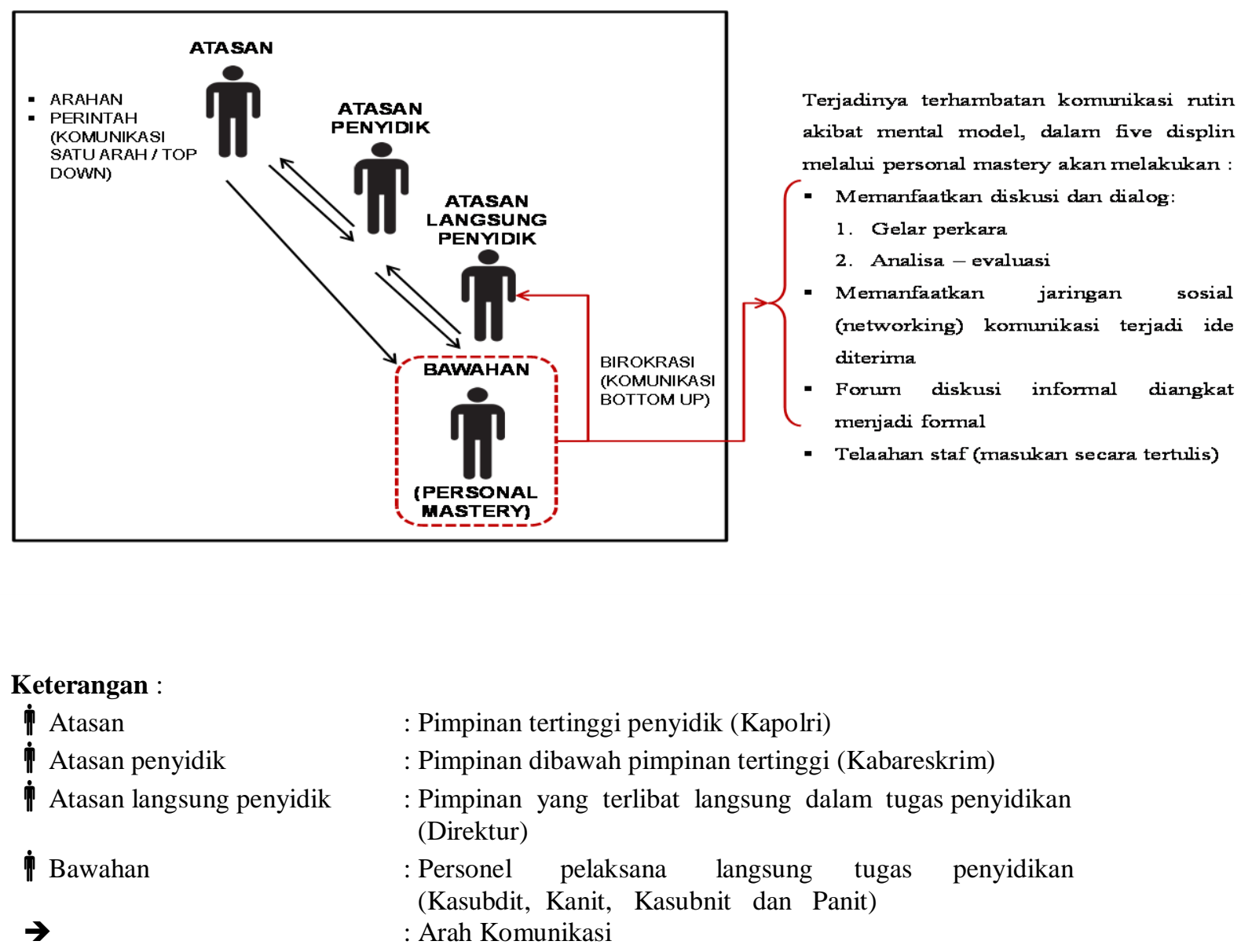

Gambar 1.

Hierarki Model Komunikasi Organisasi Bareskrim Polri

\footnotetext{
${ }^{16}$ Hubungan bersifat hirarkhi dapat diketemukan dalam hubungan lembaga yang bersifat quasi militer dan militer. Hubungan ini sesuai dengan analisa yang disampaikan oleh Roy R. Roberg dan Jack Kuykendall dalam Police and Society. Wadsworth Publishing Company, Belmont, California A Division of Wadsworth, Inc,1993, Page : 99. Mengutip pendapat dari Leonard L. Sayles dan George Strauss, Human Behavior in Organizations. Englewood Cliffs, NJ, Prentice Hall, 1996, Page 349.Roy dan Kukendall menyebutkan “ The characteristic of the classical, hierarchical (pyramidal) model include, early all contacts take the form of orders going down and reports of results going up the pyramid. Also, inviduals at any level (except at the top and bottom) have contact only with their boss above them and their subordinates below them".
} 


\section{KESIMPULAN}

Pada praktiknya setiap jenjang kepangkatan ini memiliki lambang yang berbeda, yang jelas tampak pada seragam dinas Polri. Walaupun terdapat anggota Bareskrim ketika pada tugas sehari-hari tidak menggunakan seragam dinas (un uniform police). Model hierarki tetap mengarahkan kepada siapa anggota organisasi berinteraksi dan berkomunikasi sehingga tidak dianggap salah (secara etika dan displin) baik dalam bersikap dan berperilaku khususnya dalam hubungan person to person. Disisi lain, juga mempunyai hubungan dan saling terkait yaitu mempengaruhi pengelolaan organisasi yang muncul dalam bentuk keputusan, kebijakan dan arahan baik tertulis maupun lisan.

Model hierarki komunikasi mendorong terjadinya manajemen pembelajaran yang tertib karena selain tetap membuka pola komunikasi dua arah, diskusi dan dialog serta di dalamnya ada kritik, masukan dan saran. Namun model komunikasi hierarki mensyaratkan komunikasi tersebut secara formal harus berpedoman pada etika, prosedur dan tata cara tertentu. Ditambah lagi, memberikan pembelajaran individu terkait dengan kesadaran terhadap posisi pada level tertentu untuk selalu mengkoreksi diri sendiri sebagai hal pantas dan patut yang harus dimiliki oleh dirinya dalam posisi tersebut di dalam organisasi baik yang terkait dengan kompetensi maupun integritas.Secara fungsional hiereraki komunikasi organisasi Bareskrim dapat membantu Kapolri dalam membina dan menyelenggarakan fungsi penyelidikan dan penyidikan tindak pidana, pengawasan dan pengendalian penyidikan, penyelenggaraan identifikasi, laboratorium forensik dalam rangka penegakan hukum serta pengelolaan informasi kriminal nasional.

\section{DAFTAR PUSTAKA}

Blazenaite, Aukse. 2011. Effective Organizational Communication: in Search of a System. Socialiniai Mokslai, Vol. 4 (74)

Brown, J. (1992). "Changing the Police Culture”, Journal Policing, Vol 8, No 4, Winter

Danendra, K.B.I. (2012). Kedudukan Dan Fungsi Kepolisian Dalam Struktur Organisasi Negara Republik Indonesia. Jurnal Lex Crimen Vol.I, No.4

Dewan, R., Seidmann, A., \& Sundaresan, S. (1997). Communications in Hierarchical Organizations and Standards Policies for Information Technology. International Journal of Electronic Commerce, 1(3), 43-63. Retrieved December 12, 2020, from http://www.jstor.org/stable/27750819 
Hanson, Krackhardt. Informal Network: The Company Behind the Chart, Harvard Business Review, pp.63,July/Agust,. 1993

Hinshaw, R.E. 1980. "Anthropology, Administration and Public Policy", Annual Review of Anthropology, 9: 497-522.

Johnson-laird. (1983). Mental models, Library of Congress Catalog in Publicition Data, US of America.

Leonard L. Sayles dan George Strauss. (1996). Human Behavior in Organizations. Englewood Cliffs, NJ, Prentice Hall.

Nanus, Burt and Stephen M. Dobbs .(1999). Leaders Who Make a Difference, Joosey-Boss Publisher.

Peraturan Kapolri nomor 16 tahun 2012 tentang mutasi personel Polri, dalam pasal 4 angka 2 huruf e.

Roy R. Roberg dan Jack Kuykendall dalam Police and Society. (1993). Wadsworth Publishing Company, Belmont, California A Division of Wadsworth, Inc.

Shanahan, P. (2000). "Police Culture and the Learning Organisation: A Relationship?", AVETRA Conference Papers.

Widhiastuti, H. (2012). The Effectiveness of Communications in Hierarchical Organizational Structure. International Journal of Social Science and Humanity. Vol. 2, No. 3

https://www.managementstudyhq.com/types-of-communication.html

Yahaya, Muhammad, et. al. 2018. Organizational Structure And An Effective Communication: The Moderating Effect Of Transformational Leadership. International Journal Of Scientific \& Technology Research Volume 7, Issue 11, November 2018 